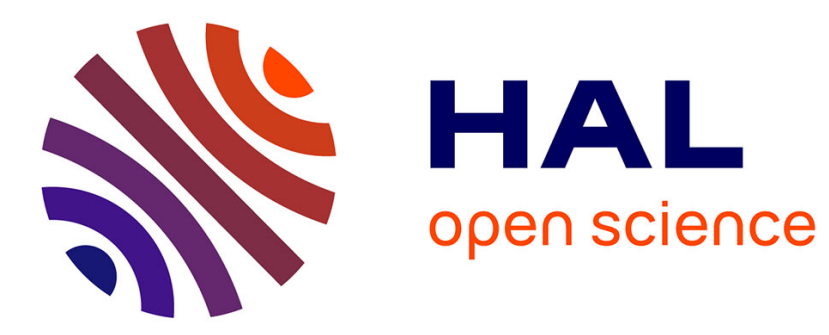

\title{
DISLOCATIONS POINT DEFECTS INTERACTIONS IN MAGNESIUM
}

\author{
A. Vincent, S. Seyed Reihani, Gilbert Fantozzi, J. Perez
}

\section{To cite this version:}

A. Vincent, S. Seyed Reihani, Gilbert Fantozzi, J. Perez. DISLOCATIONS POINT DEFECTS INTERACTIONS IN MAGNESIUM. Journal de Physique Colloques, 1981, 42 (C5), pp.C5-393-C5-398. 10.1051/jphyscol:1981559 . jpa-00221102

\section{HAL Id: jpa-00221102 https://hal.science/jpa-00221102}

Submitted on 1 Jan 1981

HAL is a multi-disciplinary open access archive for the deposit and dissemination of scientific research documents, whether they are published or not. The documents may come from teaching and research institutions in France or abroad, or from public or private research centers.
L'archive ouverte pluridisciplinaire HAL, est destinée au dépôt et à la diffusion de documents scientifiques de niveau recherche, publiés ou non, émanant des établissements d'enseignement et de recherche français ou étrangers, des laboratoires publics ou privés. 


\title{
DISLOCATIONS POINT DEFECTS INTERACTIONS IN MAGNESIUM
}

\author{
A. Vincent ${ }^{*}$, S.M. Seyed Reihani, G. Fantozzi and J. Perez \\ * Laboratoire de Traitement du Signal et d'Ultrasons, Groupe de Metalzurgie \\ Physique et Physique des Matériaux - E.R.A. 463 \\ Institut National des Sciences Appliquées, Bât. 502 - 69821 Villeurbanne \\ Cedex, France
}

\begin{abstract}
The interactions between dislocations and point defects have been studied in magnesium containing $100 \mathrm{p.p.m}$. of impurity atoms. The experiments where conducted on one hand by measuring the ultrasonic attenuation changes due to a bias stress and on the other hand by measuring the internal friction on a torsion pendulum working at $2 \mathrm{~Hz}$.
\end{abstract}

INTRODUCTION - Since few last years the studies of variation of the attenuation versus a bias stress $\Delta \alpha=f(\sigma)$ show a certain interest. This advantage with respect to the classical internal friction studies is due to the fact that the stress responsible for the dislocation motion $(\sigma)$ can be separated from that of measurement ; moreover the amplitude of measurement is very small because it is in the ultrasonic range. These ultrasonic studies leads to an interpretation usually more convincing for the obtained analastic phenomena.

The experiments has been done, until now, mainly on the c.f.c. metals as copper [1], aluminium [2,3] and recently some results were reported on a b.c.c. metal (tungsten [4]).

The aim of this investigation is to present the first results obtained on a h.c.p. metal ; moreover the results of $\Delta \alpha=f(\sigma)$ are compared with the classical internal friction spectrum $\delta=f(T)$ obtained with the same material.

EXPERIMENTAL RESULTS - 99,99\% polycrystalline magnesium has been used. The samples were annealed for two hours at $300^{\circ} \mathrm{C}$ in argon atmosphere; their dimensions were $5 \times 5 \times 70 \mathrm{~mm}^{3}$ for quasi static stress experiments and $\phi 1 \mathrm{~mm} \times 50 \mathrm{~mm}$ for internal friction measurements. For $\Delta \alpha=f(\sigma)$ measurements, the tensile quasi static stress has been applied along the same axis than that of the ultrasonic longitudinal wave (17 $\mathrm{MHz}$ ). The internal friction measurements has been performed with an inverted torsion pendulum $(2 \mathrm{~Hz})$. Dislocations were introduced in the sample by equivalent plastic deformation at $100 \mathrm{~K}(0.2 \%$ for tensile test and $0.8 \%$ on the external fibre of the sample in pendulum experiment).

At first, isochronal annealings were performed between $108 \mathrm{~K}$ and $320 \mathrm{~K}$; figure 1 shows the attenuation changes $\Delta \alpha=f(\sigma)$ measured at $108 \mathrm{~K}$ for three typical situations : (i) fifteen minutes after plastic deformation, the attenuation increases a little then decreases regularly with the stress increasing up to $6.10^{6} \mathrm{~N} \cdot \mathrm{m}^{-2}$. (ii) By annealing 15 minutes at $200 \mathrm{~K}$, the main decrease in the attenuation has disappeared. (iii) Finally after a treatment at $320 \mathrm{~K}$, a continuous and important increase in $\Delta \alpha$ appears. Furthermore, it must be noted that after these annealings at increasing temperatures, the hysteresis loop observed in the curve attenuation versus bias stress $\sigma$ is at first negative (case a) and becomes positive (case c).

On an other hand, the temperature effect on $\Delta \alpha=f(\sigma)$ after annealing at $320 \mathrm{~K}$ have been studied. Figure 2 shows two main features :

- firstly there is a rapid increase in the variations of $\Delta \alpha$ between $108 \mathrm{~K}$ and

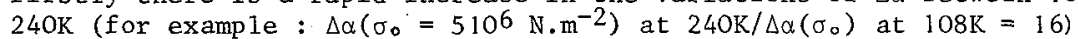


- secondly a new mechanism interferes above $240 \mathrm{~K}$, because, on one hand there is a crossing point in the loading-unloading cycle, and on the other hand the amplitude of the attenuation change seems to be reduced again above $240 K$.

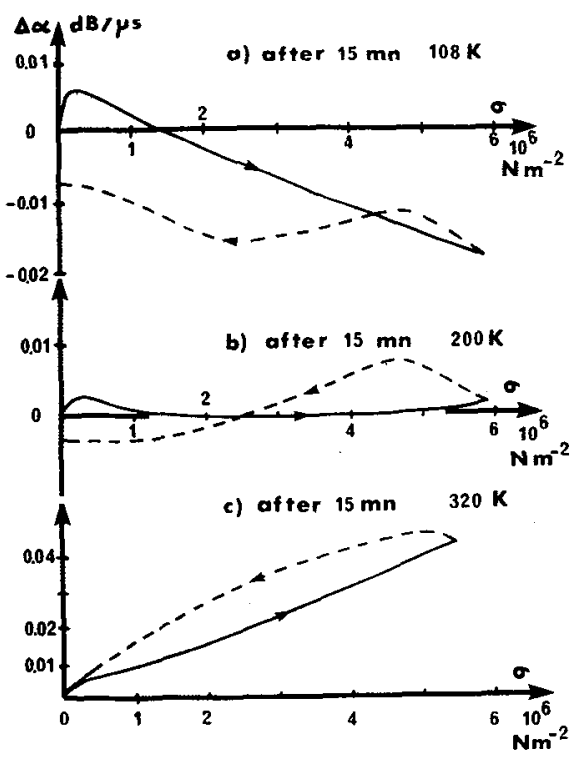

figure 1

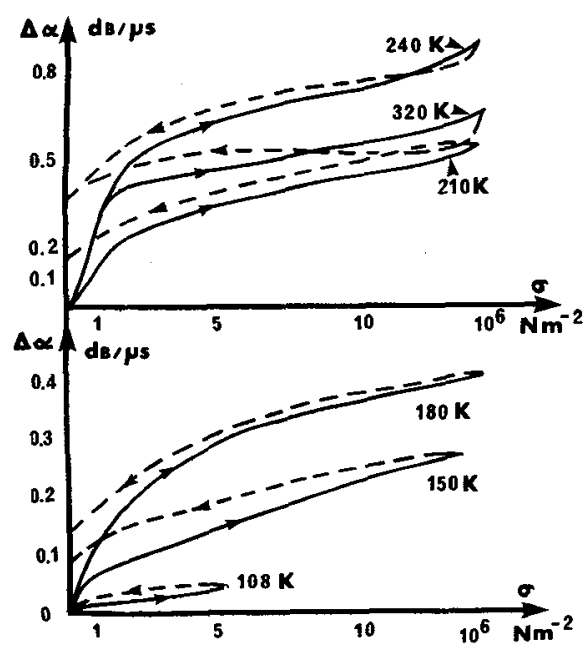

figure 2

$\Delta \alpha=f(\sigma)$ at different temperatures after treatment at $323 \mathrm{~K}$.

$\Delta \alpha=f(0)$ measured at $108 \mathrm{~K}$ after plastic deformation in situ.

In order to state the characteristics of this latter phenomenon, we have studied the effect of the loading rate $\dot{\sigma}$ at $323 \mathrm{~K}$ : the figure 3 shows that $\Delta \alpha(\sigma)$ is decreased marked1y when $\dot{\sigma}$ is lowered and also that the crossing effect disappears when $\dot{\sigma}$ is increased.

Moreover, the figure 4 presents the main characteristics of the internal friction spectra of the same material after the same plastic deformation. On one hand ( $f$ ig. 4a), we can note that the internal friction spectrum exhibits a broad maximum situated between 100 and $150 \mathrm{~K}$; there is a rather small evolution of the spectrum after some temperature cyclings up to $320 \mathrm{~K}$ : only a general decrease in the internal friction level can be mentioned especially after heating up to $320 \mathrm{~K}$. On the other hand (fig. 4b), with increasing the measurement amplitude $\varepsilon_{\mathrm{m}}$, the maximum of the internal friction shifts to a lower temperature as it is shown in the case of the spectrum obtained after heating up to $320 \mathrm{~K}$. 

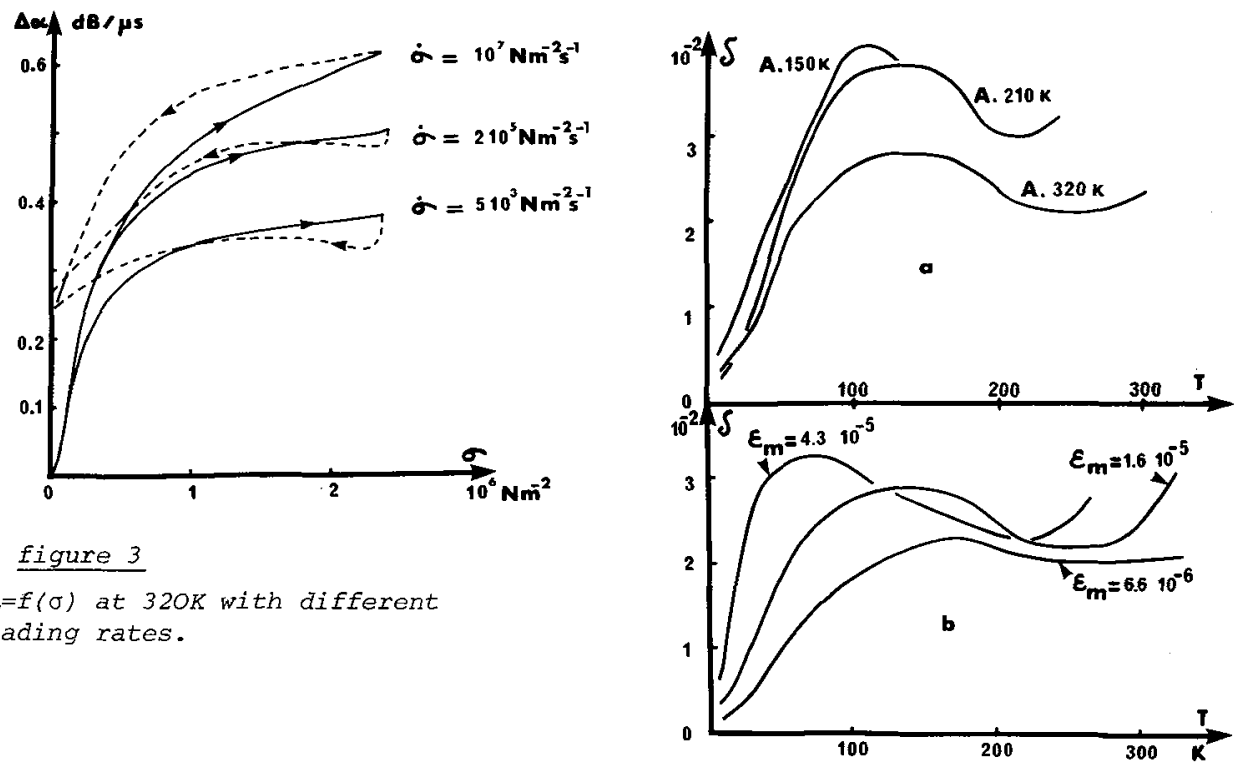

Figure 4

Iriternal friction spectrum : a) after different annealings $\left.\left(\varepsilon_{m}=1.610^{-5}\right) ; b\right)$ for different amplitude of measurement $(\varepsilon m)$, after annealing at $320 \mathrm{~K}$.

DISCUSSION - The study of the annealing stages is not the main aim of this investigation, hence, we are going to distinguish essentially the results obtained after the treatments between $100-150 \mathrm{~K}$, i.e. in the first substage of the stage IIr (usually called stage III $_{A}$ ) from that one observed after annealing in the temperature range 250 - 320K i.e. the stage IV [5].

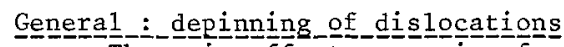

The main effect appearing from these experimental results is the depinning of dislocations from point defects. In fact, after the treatment in the stage IV, the variation $\Delta \alpha=f(\sigma)$ presents the characteristics relative to the increase of dislocation free length : it is ascribed to the depinning of dislocations under the action of the bias stress $\sigma$, as it was already shown in the case of aluminium [6]. The figure 2 shows a very important increase of this effect between 100 and $240 \mathrm{~K}$ : this enlargment of the effect must be attributed partly to the increase of the viscous Friction due to the interaction dislocations-phonons [7] and partly to the thermal activation leading to depinning of an increasing number of dislocation loops [8]. Also, it is probable that such a depinning is responsible, for an important part, of the broad maximum observed in the internal friction between 100 and $200 \mathrm{~K}$. Indeed, on one hand, if we assume a distribution in the values of the interaction parameters (interaction energy, dislocation loop length), a progressive increase $\Delta \alpha=f(\sigma)$ and a large maximum in the internal friction are expected [9]; on the other hand, this maximum shifts towards low temperatures when the oscillation amplitude increases (see fig. 4) according to the depinning mode1 [10].

The point defects involved in the depinning process are presumably extrinsic defects brought along by vacancy complexes diffusing in the stage IV of recovery; as a matter of fact this point remains to be proved by comparison with attenuation results on a purer magnesium. Nevertheless, several arguments can be put forward in agreement with this point of view : (i) the likeness with results observed with aluminium [6], (ii) the continuous decrease in the stage IV of recovery of the modulus defect measured at $20 \mathrm{~K}$ [11] and (iii) the disappearance of the broad maximum of internal friction with a purer magnesium [12]. 
11igh

In the range of room temperature (320K) the thermally activated depinning of dislocations can not explain neither the sudden decrease of attenuation observed when the stress begins to decrease, nor the rate effect ( $\sigma$ ) which is opposite to that resulting from a pure depinning (cf. fig.3). Such an effect was already observed with aluminium [2] and it can be explained by a diffusion of point defects dragged by the stress field of dislocations (fig.5c) ; this mechanism will be possible if the velocity of dislocations (given by $\mathrm{dy} / \mathrm{dt}=\sigma \cdot \mathrm{bL}^{2} / 2.0$ where $\mathscr{C}$ is the line tension and $b$ is the burgers vector) remains smaller than the maximal velocity $V_{M}$ of the point defect in the stress field of dislocation. This latter can be given by $V_{M}=v_{a} \cdot b \cdot \exp \left(-U_{d} / K T\right) \cdot \exp \left(F_{M} b / K T\right)$

where $U_{d}$ is the activation energy of diffusion andF the maximal interaction force of the dislocation with point defects and $v_{a}$ the attempt frequency. This condition $\mathrm{dy} / \mathrm{d} t \leqslant \mathrm{~V}_{\mathrm{M}}$ is more easily satisfied when $\dot{\sigma}$ is small and the temperature is elevated: the effect of these two factors are well verified experimentally on pictures 2 and 3 , because it appears that the depinning is incomplete (and thus the attenuation change reduced) for the dislocation elements concerned with this phenomenon.

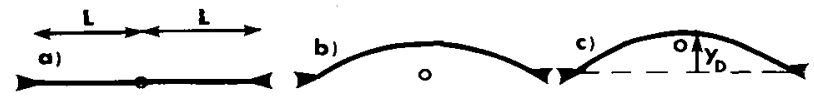

\section{Figure 5}

a) Dislocation and point defect at rest; b) dislocation fully freed by depinning; c) Dislocation partly liberated if point defect diffusion occurs.

Otherwise, the sudden decrease of the attenuation when $\sigma$ is inverted can be explained only if the idea of dislocation pinning with regard to the ultrasonic wave is precised. When the dislocation and the point defect are at rest, the dislocation is situated at the bottom of a symmetrical potential well resulting from the interaction with the point defect (fig.6 a). In the proximity of the point defect, the vibration of the dislocation loop under the action of the ultrasonic wave is strongly reduced by the return-force due to the potential well. The attenuation of this ultrasonic wave is usually calculated as in the case of the two independently vibrating segments situated at each side of the point defect (fig. 5a). When the point defect is dragged by the dislocation, it is no more situated at the bottom of this walley. In the reference system moving with the point defect, the dislocation feels a larger (and asymmetric) valley (fig.6b); the ultrasonic vibration is then less limited and the dislocation will behave as partially depinned with regard to the ultrasonic wave.

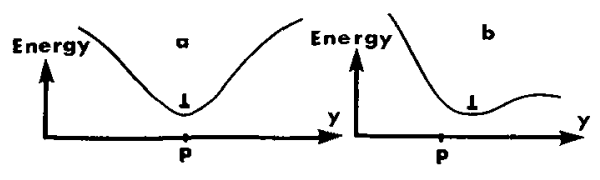

Fiqure 6

Schematic picture of a dislocation in the potential valley induced by the point defect : a) at rest ; bj if the point defect is dragged by the dislocation as in picture $5 \mathrm{c}$.

When the rate $\dot{\sigma}$ is inverted, the dislocation returns, at least temporarily, in the bottom of the valley : so at this time there is rapidly a pinning more effective of the dislocation ultrasonic vibration, that is to say a decrease of the attenuation occurs (fig. 3) [13]. 


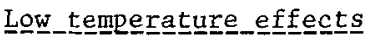

The attenuation measurements done at $108 \mathrm{~K}$ show a very different behaviour before and after treatment in the stage IV of recovery; the low frequency internal friction is not so marquedly changed by this treatment.

The attenuation effect before the high temperature treatment is generally attributed to pile up of geometrical kinks by the bias stress $\sigma$ : thus their high frequency mobility is reduced, that is to say $\alpha$ decreases as $\sigma$ increases. [14]. Nethertheless, the appearance of a small jump in attenuation (cf. fig. 1) at a very small stress $\sigma$ indicates that some depinning process is already occuring for few dislocations even without treatment in stage IV.

In fact, if we now consider the internal friction spectrum $\delta=f(T)$ after treatment in stage III at $150 \mathrm{~K}$, the broad and high maximum already observed around $110 \mathrm{~K}$ cannot be ascribed to this breakaway of few dislocations. Furthermore, the low frequency intrinsic BORDONI relaxations B1 and B2 are clearly identified in a purer material [12] at lower temperatures $(B 1 \simeq 40 \mathrm{~K}$ and $\mathrm{B} 2 \simeq 80 \mathrm{~K})$ : then they can not participate greatly to our maximum, more especially as B2 is not well developped before treatment in stage IV.

These reasons indicate that the process mainly involved in the internal friction maximum under discussion is associated with extrinsic defects but is not a pure depinning. In another connection, the negative hysteresis observed in the attenuation experiments suggests that the displacement induced by the bias stress $\sigma$ is not reversible : this means that some kinks (geometrical or thermal kinks which are responsible of the ultrasonic attenuation at 108K) could be pinned by extrinsic defects during the displacement, as drawn schematically on picture[7]: when the alternative stress of pendulum is applied, then the depinning will appear during the negative part of the oscillation; low frequency energy will be dissipated by this mechanism which may be enhanced if the dislocation oscillates between two positions, as suggested on fig. $7 \mathrm{~d}$.

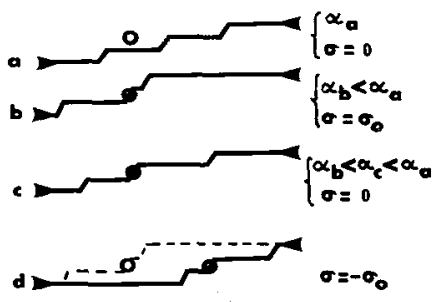

\section{figure?}

Schematic picture of kink point defect interaction and associated attenuation values

a) at rest ; b) bias stress ; c) bias stress removed; d) alternative stress as in pendulum (full line negative stress; dotted line positive stress).

CONCLUSION - Although other experiments have to be undertaken, these first results attenuation - bias stress obtained with magnesium exhibit a great similarity with that previously observed on aluminium and ascribed to the interaction dislocation point defect ; in addition, it is interesting to notice that this analogy was also observed for the intrinsic properties of dislocations [12].

ACKNOWLEDGMENTS : The authors would like to express their gratitude to Dr. REVEL who prepared the magnesium samples at the C.E.C.M. Vitry. 


\section{REFERENCES}

[1] D. LENZ, B. EDENHOFER and $K$. LUCKE Scripta. Metal1, 5,387 (1971)

[2] A. VINCENT, J. PEREZ et P.F. GOBIN J. Phys. 32, 651 (1971)

A. VINCENT et J. PEREZ

Phil. Mag. A,3,377-397 (1979)

[3] G. GREMAUD, W. BENOIT, R. GOTTHARDT Proceedings of the $3^{\text {rd }}$ European Conference I.F.U.A.S. Pergamon Press p.61-66 (1979)

[4] D.G. PINATTI and J.M. ROBERTS

Proceedings of the $6^{\text {th }}$ I.C.I.F.U.A. - Tokyo Press - p.593-597 (1977)

[5] NICOUd Thèse, ORSAY p.92 (1970)

[6] A. VINCENT, S.M. SEYED REIHANI and J. PEREZ

Phys. Stat. Sol. a,39,651-660 (1977)

(7) A. HIKATA, R.A. JOHNSON and C. ELBAUM Phys. Rev. B,2,12,4856-4863 (1970)

[8] K. LUCKE, A.V. GRANATO and L.J. TEUTONICO J. App1. Phys. 39,11,5181-5191 (1968)

[9] A. VINCENT in preparation

[10] R.R. HASIGUTI and K. IWASAKI Proceedings of the 6th I.C.I.F.U.A. - Tokyo Press p.647-651 (1977)

(11) S.M. SEYED REIHANI Thèse, LYON (1981)

〔12〕 G. FANTOZZI, S.M. SEYED REIHANI, C. ESNOUF and G. REVEL Proceedings of the $3^{\text {rd }}$ European Conference I.F.U.A.S. Pergamon Press - p.85-89 (1979)

(13) A. VINCENT in preparation

[14] A. VINCENT et J. PEREZ
J. Phys. Lett. 37,4279-4282
(1976) 